\title{
COMPENSATION DISCLOSURE ON PRODUCT REVIEW BLOGS AND PERSUASION WITH UNCERTAINTY
}

Mehdi Ghazisaeedi, Luleå University of Technology, Sweden

Esmail Salehi-Sangari, KTH- Royal Institute of Technology, Sweden

Åsa Wallström, Luleå University of Technology, Sweden

\section{INTRODUCTION}

Blogs have incredible potential as persuasion tools and their persuasive function is of great importance as they have a great influence over public opinion (Xifra \& Huertas, 2008). Individuals are increasingly referring to online product review blogs for gaining advice and receiving recommendations concerning the quality of the product of their choice. As a result, some marketers have made an effort to control or manipulate the online reputation of their products by compensating individuals to review products favorably in various online forums and product review blogs (Jensen, 2011). In return, as of late 2009, the Federal Trade Commission (FTC) has mandated product review bloggers to provide disclosures in their reviews when they receive compensation (payment or free products), or whenever there may be hidden interests or unspoken biases related to recommendations (FTC, 2009).

Now that the FTC has mandated disclosure of any compensation, the question is how marketers can overcome this obstacle. The current study investigates conditions under which the product review could gain influence even though the compensation is disclosed. Expressing certainty in a message generally increases perceived credibility of the source which in turn increases persuasive effect on its audience (Petty and Wegener 1998; Pornpitakpan 2004); however, Karmarkar and Tormala (2010) argue that this could not always be true at interpersonal level and in consumer behavior context, which usually calls for subjective judgments. Karmarkar and Tormala (2010) argue that the unexpectedness may be more important than certainty in subjective judgments.

A review of the literature reveals a long history of employing incongruity in advertising for better engaging people with the ad and more likely involving them in a detailed message-related thinking, which would lead to persuasion (Chu and Kamal, 2008; Priester and Petty, 1995; 2003; Smith and Petty 1996). The logic behind incongruity studies can be explained by the two classic dual-processing attitude change theories, namely the Elaboration Likelihood Model (ELM; Petty \& Cacioppo 1986) and the Heuristic-Systematic Model (HSM; Chaiken, Liberman, \& Eagly 1989), which provides a general framework for understanding the basic processes underlying the effectiveness of persuasive communications. Lee and Schumann (2004) show that by combining the tenets of these theories with the Mandler's Schema Incongruity Theory (1982) we can reach a better understanding of the incongruity effects in advertising and consumer behavior studies.

This research proposed an incongruity-based interaction hypothesis for the effects of compensation disclosure and source certainty on persuasion. Based on the incongruity violate expectancy theory, blog readers will experience greater expectancy violation - perceiving a message as more surprising and unexpected - when disclosure of compensation and source certainty for a product review are incongruent (e.g. disclosure of compensation/low certainty) rather than congruent (e.g. disclosure of compensation/high certainty). The result would likely be that blog readers feel more involved with a product review and perceive the blogger more credible when the disclosure of compensation and source certainty are incongruent, as opposed to congruent. Finally, as far as the product review itself contains strong arguments, greater involvement should encourage greater persuasion due to increased cognitive elaboration.

This study examines how the level of certainty expressed in product review blogs affects blog readers' elaboration of brandrelated messages and brand attitudes when compensation for a product review is disclosed. This experimental study also explores whether blog readers perceive the blogger more credible when opinions are expressed with uncertainty and compensation is disclosed.

\section{METHODOLOGY}

An experimental study was conducted in an online setting by developing four mock-up blogs to manipulate the different levels of source certainty and compensation disclosure. The experiments were undertaken on Amazon's Mechanical Turk (MTurk), which is a crowdsourcing online labor market where workers are willing to complete small or quick tasks that are posted by requesters (called Human Intelligence Tasks or HITs).

Subjects randomly assigned to one of four conditions in a 2 (compensation disclosure: disclosed versus not disclosed) $\times 2$ 
(source certainty: certain versus uncertain) between-participants factorial design. Thus, compensation disclosure and source certainty served as the two manipulated variables; and level of involvement, extent of message elaboration, favorability thoughts, attitudes toward the brand, attitudes toward the blog and perceived blogger credibility were the analyzed variables.

Participants were directed to a link to read a favorable review containing strong arguments of a fictitious travel shoe written by a fictitious blogger. Subjects randomly read one of the four blogs by clicking on the provided link. At the end of the page a unique link for each blog (condition) directed participants to a questionnaire. The questionnaire measured the dependent variables and demographic variables including gender, age, highest level of education attained, place of residency and their English language proficiency.

MTurk users with at least a 95 per cent approval rating were qualified for participating in the study from all over the world. It was explained that users would be able to participate in the experiment only once. The experiment as a HIT was available for 350 participants. Although Mechanical Turk assigns only one MTurk ID per person and allows worker IDs to accept a HIT only once, records showed that 56 responses contained the same MTurk ID. Also Qualtrics records showed that 86 responses contained the same IP address. In order to make sure that respondents did not participate in the study multiple times, all responses with the same MTurk ID and the same IP addresses were omitted. Finally, a number of 208 valid and completed surveys were collected.

\section{RESULTS AND DISCUSSION}

This experimental research attempts to investigate how the interactions between compensation disclosure and source certainty affects blog readers' involvement with the product review and whether it influences their brand-related elaboration engagement. Particularly, results indicate that a significant interaction between source certainty and compensation disclosure were qualified $(\mathrm{F}(1,204)=21.14, \mathrm{p}=.000)$. The results of this study suggested when compensation for a product review is disclosed, blog readers are more involved with the product review when opinions are expressed with uncertainty $(\mathrm{M}=5.81)$ rather than by certainty $(\mathrm{M}=5.037)$.

Respectively analysis of the thought-favorability revealed a significant interaction between source certainty and compensation disclosure $(\mathrm{F}(1,204)=20.89, \mathrm{p}=.000)$. This open-ended thought-listing procedure demonstrated that when compensation for a product review is disclosed, blog readers' thoughts were more favorable when opinions were expressed with uncertainty $(\mathrm{M}=1.68)$ than by certainty $(\mathrm{M}=.150)$.

In each of our conditions source incongruity boosted greater persuasion, suggesting that when compensation is disclosed, bloggers can gain interest and influence readers by expressing uncertainty, whereas when compensation is not disclosed, bloggers can gain interest and influence readers by expressing certainty.

Furthermore, this study attempts to examine how the interaction between compensation disclosure and source certainty affects blog readers' brand attitudes. Results show a significant interaction between source certainty and compensation disclosure $(\mathrm{F}(1,204)=15.73, \mathrm{p}=.000)$. Results indicate that the brand attitudes of participants who read the product review containing the compensation disclosure statement were more influenced by opinions that were expressed with uncertainty $(\mathrm{M}=5.86)$ rather than by certainty $(\mathrm{M}=5.34)$.

Also, the results confirmed that the level of involvement mediated the attitudes towards the brand; similar thought favorability mediated the persuasion outcome.

Moreover, this study finds the interaction between compensation disclosure and source certainty influences blog readers' attitudes toward the blog itself. In this case there was a significant interaction between source certainty and compensation disclosure $(\mathrm{F}(1,204)=14.40, \mathrm{p}=.000)$. The results confirmed that participants, who read the product review with the compensation disclosure declaration, were more influenced by opinions that were expressed with uncertainty $(M=5.78)$ than by certainty $(\mathrm{M}=5.16)$.

In addition, this research investigates how the interaction between compensation disclosure and source certainty influences credibility of the author. Surprisingly a significant interaction between certainty and compensation disclosure were qualified $(\mathrm{F}(1,204)=12.424, \mathrm{p}=.001)$. The results confirmed that, when compensation for a product review is disclosed, blog readers perceive the blogger more credible when opinions are expressed with uncertainty $(M=5.94)$ rather than by certainty $(\mathrm{M}=5.34)$. 


\section{CONCLUSIONS AND IMPLICATIONS FOR THEORY AND PRACTICE}

An incongruity interaction effect of the compensation disclosure and source certainty on persuasion was hypothetized in this study. Meaning that, in general it is expected that sponsored bloggers are certain about their opinions, and it is surprising to hear a blogger disclose compensation for a product review while at the same time expressing doubt in his or her opinions.

Thus according to the incongruity violate expectancy theory, violated expectancies increase the interest in the product review and, if the message itself is supported by strong arguments, it may boost persuasion. This study shows that the incongruity between compensation disclosure and source certainty can create an effective message and enhances greater persuasion.

Therefore, the effect of compensation disclosure is not necessarily negative for bloggers and their affiliated companies. By adding a tone of uncertainty in product reviews, bloggers can change the threats to opportunities for both themselves and their sponsors. Product review bloggers who are engaged in affiliate marketing operations can declare compensation disclosure with more confidence and simultaneously write a more realistic review and create credibility for themselves.

Based on the results of this study, they can convince their affiliated companies that the incongruity in their product review posts can generate more positive evaluations for both their blog and the advertised brand. On the other hand, marketing executives and brand managers can be more confident that if a review were written about their products, containing strong arguments in an uncertain voice, the image of their brand would not be damaged. This may give them the capacity to better distinguish between a commercial ad and a paid product review.

\section{REFERENCES}

Chaiken, S., Liberman, A. and A. H. Eagly. 1989. Heuristic and Systematic Processing within and beyond the Persuasion Context, in Unintended Thought, ed. James S. Uleman and John A. Bargh, New York: Guilford, 212-252.

Chu, S. and S. Kamal. 2008. "The effects of perceived blogger credibility and argument quality on message elaboration and brand attitudes: An exploratory study.” Journal of Interactive Advertising, 8(2): article 3.

Federal Trade Commission. 2009. Guides Concerning the Use of Endorsements and Testimonials in Advertising, in 16 CFR Part 255, 2009.

Jensen, M. L. 2011. The Effects of Compensation Disclosure and Consensus on Perceptions of Online Product Reviews. Proceedings of the 44th Hawaii International Conference on System Sciences, 4-7 Jan. 2011, pp. 1-10, Kauai, HI.

Karmarkar, U. R. and Z. L. Tormala. 2010. “Believe Me, I Have No Idea What I'm Talking About: The Effects of Source Certainty on Consumer Involvement and Persuasion.” Journal of Consumer Research 36(6): 1033-1049.

Lee, E. J. and D. W. Schumann. 2004. "Explaining the special case of incongruity in advertising: combining classic theoretical approaches.” Marketing Theory 41(1/2): 59-90.

Mandler, G. 1982. “The Structure of Value: Accounting for Taste.”, in H. Margaret, S. Clarke and S.T. Fiske (eds) Affect and Cognition: The 17th Annual Carnegie Symposium on Cognition, pp. 3-36. Hillsdale, NJ: Lawrence Erlbaum.

Petty, R. E. and J. T. Cacioppo. 1986. Communication and Persuasion: Central and Peripheral Routes to Persuasion, New York: Springer.

Petty, R. E. and D. T. Wegener. 1998. Attitude Change: Multiple Roles for Persuasion Variables, in The Handbook of Social Psychology, 4th ed., ed. Daniel Gilbert, Susan Fiske, and Gardner Lindzey, New York: McGraw-Hill, 323-90.

Pornpitakpan, C. 2004. “The Persuasiveness of Source Credibility: A Critical Review of Five Decades’ Evidence.” Journal of Applied Social Psychology 34 (2): 243-81.

Priester, J. R. and R. E. Petty. 1995. "Source Attributions and Persuasion: Perceived Honesty as a Determinant of Message Scrutiny.” Personality and Social Psychology Bulletin 21(6): 637-654.

Priester, J. R. and R. E. Petty. 2003. “The Influence of Spokesperson Trustworthiness on Message Elaboration, Attitude 
Strength, and Advertising Effectiveness.” Journal of Consumer Psychology 13: 408-421.

Smith, S. M. and R. E. Petty. 1996 "Message Framing and Persuasion: A Message Processing Analysis.” Personality and Social Psychology Bulletin 22 (March): 257-68.

Xifra, J. and A. Huertas. 2008. "Blogging PR: An Exploratory Analysis of Public Relations Weblogs.” Public Relations Review 34(3): 269-275. 